\title{
Video-assisted harvesting of internal thoracic artery through median sternotomy incision in pectus excavatum
}

\author{
Burak Onan (D), Ersin Kadiroğulları (D), Serdar Başgöze (D), Adem Reyhancan (D) \\ University of Health Sciences, Department of Cardiovascular Surgery, Istanbul Mehmet Akif Ersoy Thoracic and Cardiovascular Surgery Training and Research Hospital, Istanbul, Turkey
}

Received: November 07, 2017 Accepted: February 27, 2018 Published online: April 24, 2019

\begin{abstract}
Pectus excavatum is the most common deformity of the chest wall, in which the sternum and ribs show an abnormal growth. This pathology may complicate the operative exposure and manipulation during LITA harvesting through the median sternotomy incision in coronary artery bypass surgery. A 60 -year-old female patient with three-vessel coronary disease and pectus excavatum was admitted. The patient underwent myocardial revascularization through median sternotomy, however, the exposure of the left internal thoracic artery was unsatisfactory due to the pectus deformity. Therefore, a 30-degree endoscope was successfully used for in situ harvesting of the left internal thoracic artery. In conclusion, the use of an endoscope is a safe and feasible solution for in situ internal thoracic artery harvesting in patients with pectus deformity who undergo coronary artery bypass grafting using sternotomy.
\end{abstract}

Keywords: Coronary artery bypass grafting; internal thoracic artery; pectus excavatum; video-assisted surgery.

The internal thoracic artery (ITA) is the preferred conduit of choice in coronary artery bypass grafting (CABG). Compared to other alternative conduits, the ITA provides the highest long-term patency and event-free survival. ${ }^{[1]}$ Technically, the ITA is harvested under direct vision using a median sternotomy incision, although endoscopic techniques are frequently used in minimally invasive approaches, particularly through a left anterior small thoracotomy. ${ }^{[2]}$ However, sternal depression in pectus excavatum may prevent optimal surgical exposure for ITA harvesting under direct vision. In such cases, endoscopic techniques may facilitate mobilization of the ITA graft from the chest wall through a sternotomy incision.

Herein, we report a case of three-vessel coronary disease and pectus excavatum in whom a 30 -degree endoscope was successfully used for in situ harvesting of the ITA.

\section{CASE REPORT}

A 60-year-old female presented with progressive chest discomfort. Her past medical history included ischemic heart disease, hypertension, and diabetes mellitus. On admission, blood pressure and heart rate were $110 / 62 \mathrm{mmHg}$ and $46 \mathrm{bpm}$, respectively. Physical examination revealed mild pectus excavatum and kyphoscoliosis. Cardiac auscultation revealed displaced heart sounds in the left hemithorax. Chest X-ray showed cardiomegaly. Transthoracic echocardiography demonstrated an ejection fraction of $45 \%$ and mild mitral regurgitation. Coronary angiography revealed significant stenosis of the left anterior descending, obtuse marginal, and right coronary arteries. The patient was scheduled for an elective CABG through sternotomy. As the patient had mild-degree pectus excavatum, sternotomy incision was considered feasible. A written informed consent was obtained from the patient.

Under general anesthesia, a median sternotomy incision was performed and the lower half of the sternum was found to be depressed symmetrically. A sternal retractor (Aygun Surgical Instruments Co. Inc., Samsun, Turkey) was placed; however, the exposure of the left ITA was unsatisfactory, despite

Corresponding author: Burak Onan, MD. SBÜ İstanbul Mehmet Akif Ersoy Göğüs Kalp ve Damar Cerrahisi Eğitim ve Araştırma Hastanesi, Kalp ve Damar Cerrahisi Kliniği, 34303 Küçükçekmece, İstanbul, Turkey.

Tel: +90 553 - 6223878 e-mail: burakonan@hotmail.com

\section{Citation:}

Onan B, Kadiroğulları E, Başgöze S, Reyhancan A. Video-assisted harvesting of internal thoracic artery through median sternotomy incision in pectus excavatum. Cardiovasc Surg Int 2017;4(3):39-42. 


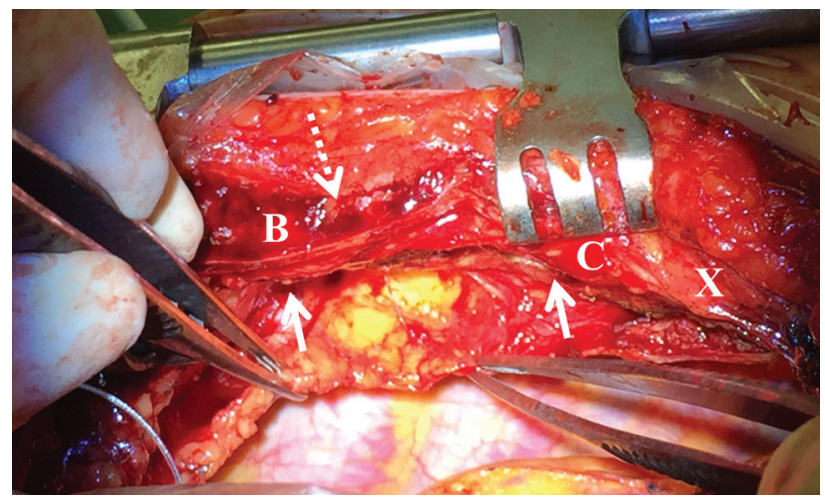

Figure 1. An intraoperative view showing that bone (B) of sternum and cartilage tissue (C) makes a depression (dotted-arrow) inferiorly. The left internal thoracic artery (between two white arrows) is behind left hemisternum (X= Xiphoid process).

maximal retraction and lifting the left side of the chest up. The direct vision of the ITA was unable to be achieved due to the depressed sternal bone in front of the graft (Figure 1). Coexistence of mild kyphoscoliosis might have also affected the surgical view. Rather than using a venous graft or other alternative conduits, we insisted on using an in situ left ITA graft for the left anterior descending artery. Therefore, a 30-degree endoscope (Evis Exera II Video System Cv-180, Olympus Medical Systems Corp., Tokyo, Japan) was used to expose the endothoracic wall and the ITA behind the depressed sternal bone. This instrument is a thoracoscope which can be used in the cardiothoracic surgery setting. The instrument was introduced into the chest cavity through the median sternotomy incision after placement of the chest retractor. The left pleura was, then, opened. An assistant surgeon directed and manipulated the endoscope helping the surgeon during the ITA harvesting. The endoscopic screen was placed on the left side of the patient and in front of the surgeon which allowed a good endoscopic view, and the pedicle of ITA was retracted inferiorly and its side-branches were gently cauterized (Figure 2). At the end of procedure, the ITA was transected distally and there was a pulsatile-free ITA flow of $60 \mathrm{~mL} / \mathrm{min}$. No graft injury or adventitial hematoma was evident macroscopically. Hemostasis of the thoracic wall was also performed endoscopically. Three-vessel coronary revascularization was performed uneventfully using cardiopulmonary bypass and cardiac arrest. The sternum was closed using the sternal steel wires after placing the chest tube. The postoperative course was uneventful and the patient was discharged on postoperative Day 6.

\section{DISCUSSION}

Pectus excavatum is the most common congenital chest wall malformation. ${ }^{[2,3]}$ Depending on the severity of pathology, chest wall depression may complicate the operative exposure of the ITA following a sternotomy incision which makes harvesting of the ITA difficult under direct vision in $\mathrm{CABG}$. In the literature, pectus deformity in patients undergoing open heart surgery has been described in several reports. ${ }^{[3]}$ In such cases, the authors recommend the use of left thoracotomy approach for harvesting of the ITA under direct vision or using endoscopic techniques. ${ }^{[2]}$ These approaches can be also used in hybrid revascularization strategy for multi-vessel disease and in high-risk patients for
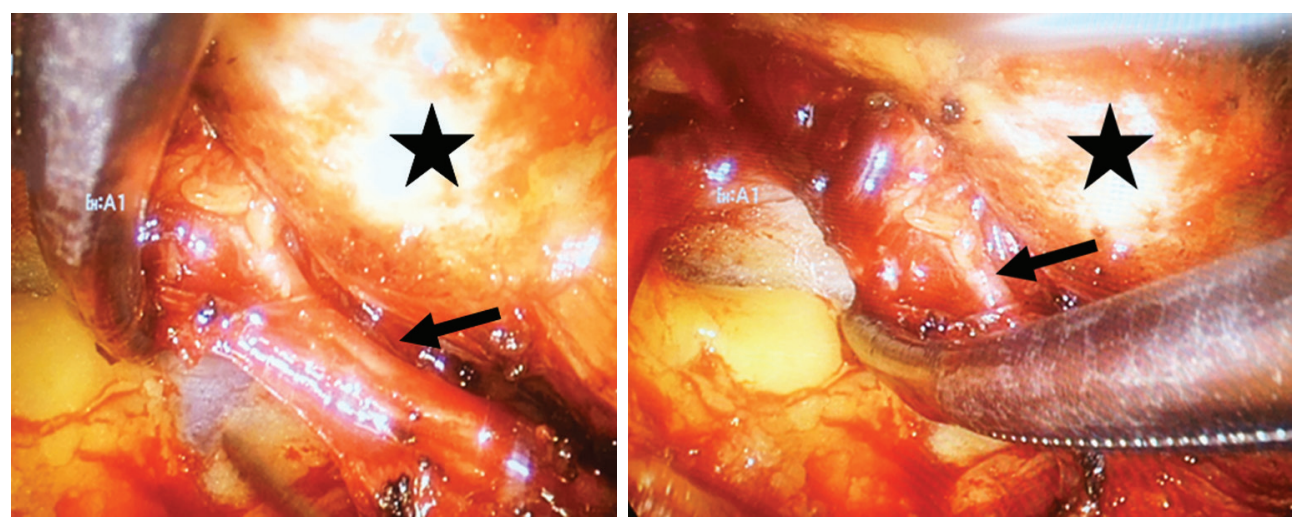

Figure 2. An endoscopic view showing internal thoracic artery (black arrow) harvesting using a 30-degree endoscope. The exposure of the artery and its side branches were improved with endoscopic vision which showed the artery behind the depressed sternum (black star). The artery was retracted inferiorly using an angled-clamp and side-branches were cauterized uneventfully. 
a sternotomy incision in pectus excavatum. In this report, we described an alternative approach to obtain a good ITA exposure through a sternotomy incision in pectus excavatum using a 30-degree endoscope.

The technique of ITA harvesting may vary according to the revascularization approach applied. In patients with single vessel-disease and pectus excavatum, a left-sided mini-thoracotomy incision or endoscopic approaches can be used..$^{[3,4]}$ The effectiveness and safety of endoscopic approaches for ITA harvesting have been shown previously. ${ }^{[5]}$ It has been also reported that the use of endoscopic approach does not jeopardize the quality of coronary anastomosis and late graft patency. ${ }^{[2]}$ An additional benefit of the endoscopic approach is decreased postoperative pain, compared to the direct-vision approach. ${ }^{[6]}$ However, the necessity of the right coronary artery or multivessel revascularization, repair of combined cardiac pathologies, and the need of using right ITA require a sternotomy incision. In such cases, our alternative endoscopic approach may be useful for harvesting of the ITA.

Technically, sternal depression in pectus deformity is a limitation for ITA harvesting under direct vision, despite maximal sternal retraction and positional maneuvers. In conventional $\mathrm{CABG}$ procedures, the use of classical sternal retractors may be unsatisfactory for the exposure of the ITA. Alternatively, the use of asymmetric sternal retractors, such as Rultract (Rultract Inc., Cleveland, $\mathrm{OH}$, USA), may be feasible in pectus excavatum. These retractors directly elevate the left hemisternum away from the surgeon side to enhance the visibility of ITA. The anterior chest wall may also evert externally, which facilitates the exposure of ITA in mild pectus deformity. Nevertheless, harvesting of the ITA can be challenging in severe forms of pectus excavatum. Our approach with a 30-degree endoscope can be used concomitantly with these retractors, offering an uneventful ITA harvesting. Harvesting time is similar to conventional approach and, thus, does not impact the overall duration of the surgical procedure. The use of an endoscope seems to be a reasonable solution for ITA harvesting. However, some surgeons may have a concern about experience with the use of endoscopic screen during the ITA harvesting.

As an alternative approach, robotic harvesting of the left ITA can be considered in patients with pectus deformity. Asymmetrical chest wall, abnormal presentation of intercostal spaces, increased displacement of the heart toward the left hemithorax and associated pulmonary hypoplasia in certain patients are the major concerns for the feasibility of robotic ITA harvesting. In pectus patients, the lower ribs may present with abnormal growth of the cartilage which attaches the sternum to the ribs. This may cause an asymmetrical chest wall and narrowing of the left chest cavity. Intercostal spaces should be anatomically suitable for port placement, and the volume of the left hemithorax should be high enough for manipulations of the robotic instruments within the left chest cavity. In addition, the intercostal spaces may be small to place three ports (a camera and two arms) for docking procedures. As the heart moves to the left chest, port placement can be difficult and gas insufflation into the chest cavity may not be effective to expose the left ITA due to the malposition of the heart. Therefore, in robotic surgery, the major technical issue is the degree of the chest wall deformity. In mild-degree deformities, robotic approach can be considered. However, this can be a challenge in moderate or severe-degree deformities. In mild forms of pectus deformity, robotic ITA harvesting can be considered and coronary procedure can be performed using a mini-thoracotomy incision in single-vessel disease or using a sternotomy incision in multi-vessel coronary artery disease.

Pectus deformity in patients undergoing open heart surgery has been subject of several reports in the literature, usually combined with repair of pectus deformity itself. ${ }^{[3]}$ A median sternotomy incision should be reserved for a mild or moderate form of sternal deformity, unless a decision is made to repair the pectus prior to closing sternum. In the presence of severe deformity, the use of sternotomy incision for cardiac surgery and simultaneous repair of chest deformity may be a reasonable approach to avoid severe sternal or cardiopulmonary complications postoperatively. Schmidt et al. ${ }^{[3]}$ reported that simultaneous pectus excavatum correction and cardiac surgery was effective and reliable. A combined approach is advocated, if candidates for cardiac surgery present with significant pectus excavatum deformity. In the present case, such a pectus repair was obviously not necessary, and the use of endoscope enabled a takedown of the left ITA for coronary revascularization.

In conclusion, the use of an endoscope is a safe and feasible solution for in situ internal thoracic artery harvesting in patients with pectus deformity 
undergoing coronary artery bypass grafting using a sternotomy incision. It may be also beneficial in pectus cases with a limited number of alternative conduits for coronary artery bypass grafting, as well as reoperations.

\section{Declaration of conflicting interests}

The authors declared no conflicts of interest with respect to the authorship and/or publication of this article.

\section{Funding}

The authors received no financial support for the research and/or authorship of this article.

\section{REFERENCES}

1. Aldea GS, Bakaeen FG, Pal J, Fremes S, Head SJ, Sabik $\mathrm{J}$, et al. The society of thoracic surgeons clinical practice guidelines on arterial conduits for coronary artery bypass grafting. Ann Thorac Surg 2016;101:801-9.
2. Hrapkowicz T, Bisleri G. Endoscopic harvesting of the left internal mammary artery. Ann Cardiothorac Surg 2013;2:565-9.

3. Schmidt J, Redwan B, Koesek V, Aebert H, Tjan TD, Martens S, et al. Pectus excavatum and cardiac surgery: simultaneous correction advocated. Thorac Cardiovasc Surg 2014;62:238-44.

4. Kim PY, Wittwer T, Haverich A, Cremer JT. Coronary revascularization without cardiopulmonary bypass in patients with pectus excavatum. Ann Thorac Surg 1999;68:470-2.

5. Bonatti J, Schachner T, Bonaros N, Oehlinger A, Wiedemann $\mathrm{D}$, Ruetzler E, et al. Effectiveness and safety of total endoscopic left internal mammary artery bypass graft to the left anterior descending artery. Am J Cardiol 2009;104:1684-8.

6. Bucerius J, Metz S, Walther T, Falk V, Doll N, Noack F, et al. Endoscopic internal thoracic artery dissection leads to significant reduction of pain after minimally invasive direct coronary artery bypass graft surgery. Ann Thorac Surg 2002;73:1180-4. 